\title{
INTERFERÊNCIA DA AUTOIMAGEM DO BIBLIOTECÁRIO ESCOLAR NA MEDIAÇÃO DA INFORMAÇÃO
}

\author{
LA INTERFERENCIA DE LA AUTOIMAGEM DEL \\ BIBLIOTECARIO ESCOLAR EN LA MEDIACIÓN DE LA \\ INFORMACIÓN
}

\author{
João Arlindo dos Santos Neto* \\ Tatiane de Fatima Farina**
}

\begin{abstract}
RESUMO
Introdução: Analisa a autoimagem do bibliotecário escolar das escolas particulares e públicas de Londrina. Discute os termos autoimagem, imagem e autoestima no contexto do profissional da informação.

Objetivos: Investiga se a autoimagem dos bibliotecários escolares interfere na mediação da informação e verifica como essa interferência ocorre nos processos e nas práticas informacionais.

Metodologia: Apresenta uma pesquisa qualitativa de caráter descritivo, a partir de uma revisão bibliográfica e, também, exploratória. Utiliza a pesquisa de campo como método e o questionário com questões abertas e fechadas para coleta de dados.

Resultados: Constata que os bibliotecários escolares são influenciados em suas ações pela autoimagem, bem como outros fatores interferem na mediação, como a imagem e a autoestima do profissional.

Conclusões: Conclui que a autoimagem do bibliotecário escolar interfere na mediação da informação. A imagem do bibliotecário, por sua vez, também é construída a partir de seus atos mediativos e a autoestima do bibliotecário contribui para a construção de sua imagem profissional.
\end{abstract}

Palavras-chave: Autoimagem. Autoimagem do bibliotecário. Bibliotecário escolar. Mediação da Informação. Biblioteca escolar.

* Doutorando no Programa de Pós-Graduação em Ciência da Informação da Universidade Estadual Paulista (UNESP/Marília). Professor do Departamento de Ciência da Informação da Universidade Estadual de Londrina (UEL). E-mail: santosneto@uel.br.

** Pós-graduanda em Nível de Especialização em Contação de Histórias e Literatura Infantil. Bacharel em Biblioteconomia pela Universidade Estadual de Londrina (UEL). E-mail: tatyane ff@hotmail.com.

Inf. Prof., Londrina, v. 5, n. 1, p. $26-51$, jan./jun. 2016.

http:www.uel.br/revistas/infoprof/ 


\section{INTRODUÇÃO}

A imagem do bibliotecário na sociedade ainda não é reconhecida de igual forma, existem aqueles que relacionam a esse profissional a figura de uma senhora de óculos, com coque no cabelo e sentada atrás do balcão pedindo silêncio, quando não está guardando livros e tirando pó deles. No entanto, essa imagem não condiz mais com a realidade. Sabe-se da existência de muitos profissionais que contribuem para a construção de uma nova imagem da classe bibliotecária.

A imagem de um profissional é construída a partir de seus atos e comportamentos. Se o bibliotecário possui uma determinada imagem, talvez seja porque represente essa imagem para sua comunidade. Além disso, acredita-que tanto a autoimagem e a autoestima do bibliotecário, são elementos que influenciam na construção da imagem desse profissional. Como consequência, a mediação da informação que é realizada pelos bibliotecários pode sofrer interferência desses fatores, em especial, a autoimagem.

Todo profissional quando desempenha uma função ou desenvolve um produto e/ou serviço, precisa se preocupar com a sua autoimagem. Por sua vez, se ela estiver abalada, o seu desempenho não será o mesmo. Da mesma forma, se sua autoestima não for positiva, ela interferirá diretamente na autoimagem e imagem profissional.

O presente artigo investiga se a autoimagem dos bibliotecários escolares interfere na mediação da informação e analisa como essa interferência ocorre nos processos e nas práticas informacionais.

Apesar de várias mudanças nas atitudes de muitos bibliotecários, ainda há a necessidade de modificações em alguns comportamentos que tornam a imagem da profissão pejorativa, isto é, algumas atitudes negativas ainda constituem a formação da imagem do bibliotecário. $O$ papel do bibliotecário não é apenas realizar as tarefas rotineiras de uma biblioteca, mas mediar a informação com o intuito de satisfazer as 
necessidades informacionais dos usuários, como também esperar que a apropriação da informação seja alcançada pelos usuários.

Essa mediação se dá não só no atendimento, isto é, no contato com os usuários, mas em todo fazer profissional do bibliotecário, como também no seu comportamento e nas suas atividades, fazendo com que os usuários percebam a sua presença e a interferência no ambiente em que estão inseridos. Almeida Júnior (2008, p. 46) afirma que "[...] a mediação não estaria restrita apenas as atividades relacionadas diretamente ao público atendido, mas em todas as ações do profissional bibliotecário, em todo fazer desse profissional."

A mediação está envolta no dia a dia da biblioteca e do bibliotecário, devido a necessidade informacionais que os usuários que a frequentam possuem, mas também daqueles que em potencial, independentemente se são alunos, pais, professores e/ou colaboradores da escola.

Algumas pessoas são ensinadas a utilizarem as bibliotecas nas escolas desde pequenas, acompanhadas pelos professores, nesse local os alunos possuem um tempo para lerem, ouvirem histórias e realizarem outras atividades lúdicas. Portanto, ainda assim a biblioteca é vista como cenário de castigo, normalmente os bibliotecários são vistos como pessoas mal humoradas e que não fazem interação com seu usuário.

Devido a essa concepção em relação aos bibliotecários, é que se investigou a alguns conceitos existentes quanto a autoimagem desses profissionais, a partir de questionamentos aos profissionais que exercem sua função em bibliotecas escolares na cidade de Londrina/ PR.

Justifica-se esta pesquisa também pelo fato de que a preocupação com a imagem e autoimagem se faz cada vez mais presente nas organizações a fim de identificar o perfil comportamental do profissional, seu estilo de trabalho e de relacionamento, seu potencial para aproveitar o melhor que este profissional tem a oferecer.

Defende-se que é necessário investigar como a autoimagem dos bibliotecários interfere na mediação da informação, pois, sua atuação implicará na sua própria imagem. A maneira que os usuários serão 
atendidos e como a informação será mediada para ele, faz toda a diferença no momento do atendimento ao usuário e, consequentemente, para a formação da imagem do bibliotecário.

A partir do contexto apresentado, direciona-se a presente discussão para o referencial teórico deste artigo, que discute os seguintes termos: imagem, autoimagem e autoestima; mediação da informação e a interferência do bibliotecário; e biblioteca escolar.

\section{IMAGEM, AUTOIMAGEM E AUTOESTIMA DO BIBLIOTECÁRIO}

Por mais que houveram mudanças no comportamento do bibliotecário que o colocam como mediador de informação, ainda há uma concepção equivocada em relação esse profissional. No entanto, ele "[...] deixou, há muito, de ser simplesmente o guardião de livros, para tornar-se o mediador entre usuários e informação; e muito mais que isso ele possui os papéis de: promotor de leitura, educador, agente cultural e gestor da informação." (LIMA; LIMA, 2009, p. 13).

Quando se busca por imagem ou autoimagem do bibliotecário o que mais se encontra na literatura são os aspectos negativos, por exemplo: o não reconhecimento da profissão, a falta de interesse em atualizar-se sobre a área, faixa salarial baixa, entre outros. Ainda as opiniões e características estigmatizadas permanecem, bem como a cobrança pelo reconhecimento profissional, valorização social etc. Entre esses elementos, de acordo com Walter e Baptista (2007, p. 30),

[...] o aspecto visual e comportamental dos bibliotecários realmente permeia o imaginário popular, associando a profissão a mulheres, em geral idosas e, especialmente, com dois adereços principais, como uma espécie de marca registrada, que são os indefectíveis óculos e o famigerado coque nos cabelos, além de uma postura geralmente antagônica e pouco receptiva para os usuários, provavelmente em gesto que indique um enfático pedido de silêncio. 
A preocupação com a imagem e também com a autoimagem existe em diversos ambientes, sejam eles profissionais, organizacionais e, até mesmo informacionais. O dentista procura manter seus dentes limpos e saudáveis, pois os pacientes esperam ver nele um modelo, um exemplo de saúde bucal. Nutricionista busca uma alimentação saudável, pois seus pacientes esperam que ele seja uma referência em educação alimentar. Personal trainner pratica atividades físicas e procura manter o corpo em boa forma. Essa preocupação em relação a imagem profissional ocorre com diversos profissionais, e acredita-se que o mesmo aconteça com os bibliotecários. É preciso que estes profissionais se atentem para a imagem que estão passando para seus usuários, ela pode ser influenciada por diversos fatores, como mau humor no atendimento, falta de interesse em buscar informações assim por diante.

A imagem do bibliotecário sofre forte influência do estereótipo vigente socialmente, relacionado a guarda de livros e documentos. Vale ressaltar que o estereótipo também é veiculado em filmes, livros, revistas, telenovelas e comerciais televisivos, esse estereótipo tem reflexo na visibilidade da profissão e, de certo modo, contribui para a representação social do bibliotecário.

Segundo Oliveira (2010, p. 12) "A imagem do bibliotecário ainda como uma velhinha, mal encarada, recalcada, de uma verdadeira bruxa protetora dos livros que trabalha num covil escuro e silencioso repreendendo qualquer manifestação sonora, ainda está presente atualmente [...]." Esta imagem infelizmente ainda, em muitos casos, permanece.

Em relação a transformação da imagem estereotipada do bibliotecário, Grogan (1995, p. 12) afirma que a melhor maneira é "[...] mudar a realidade por trás da imagem e deixar que esta cuide de si mesma." Essa mudança depende do bibliotecário, uma vez que havendo interação entre ele e o usuário a modificação da imagem ocorre quase que de maneira natural. 
Para que se realize essa mudança, é necessário que os bibliotecários tomem consciência de sua própria importância, principalmente no ambiente em que atuam, pois as suas atividades fazem toda diferença na forma como seus usuários o reconhecem, sendo imprescindível seu envolvimento na execução dessas ações.

Quanto a autoimagem, Ferreira (2009, p. 232) afirma que o termo é formado por dois vocábulos: "a) aut(o): de si mesmo; usado como elemento antecedente de composição; b) imagem: aquilo que imita ou representa pessoa ou coisa." A união desses dois verbetes destaca a concepção que o indivíduo tem de si mesmo, ou a noção do seu próprio valor. Deste modo, compreende-se que autoimagem do bibliotecário é a representação de si mesmo, "[...] expresso no somatório de fatores que indicam seus valores ocupacionais e atitudes a respeito da Biblioteconomia." (OLIVEIRA, 1983, p. 11).

De acordo com Targino (2006) tantas outras profissões, embora bem mais atuais, foram facilmente absorvidas positivamente pela sociedade, mas a Biblioteconomia parece que estagnou no tempo, continua envolta numa nuvem estereotipada, ela ainda não está clara na mente das pessoas. Contudo, julga-se necessário atualizar as pessoas com o intuito de mostrar que a Biblioteconomia passou por mudanças significativas e que possibilita formar bibliotecários com visões diferentes, interagindo com os usuários e, também, utilizando as tecnologias para mediar a informação.

De acordo com Gouveia et al. (2005, p. 233) "A auto-imagem expressa à percepção que a pessoa tem de si, sendo definida em termos de uma constelação de pensamentos, sentimentos e ações acerca do relacionamento do indivíduo com outras pessoas [...]". Acredita-se na impossibilidade da argumentação sobre a autoimagem sem mencionar a autoestima, elas estão diretamente relacionadas, um indivíduo com a autoestima elevada possivelmente terá uma autoimagem positiva.

O termo autoimagem, segundo Mosquera e Stobäus (2008, p. 116) serve como fundamento para a autoestima, visto que "[...] reside no 
conhecimento individual de si mesmo e no desenvolvimento das próprias potencialidades, na percepção dos sentimentos, atitudes e ideias que se referem à dinâmica pessoal."

Por sua vez, a autoestima está imbricada com outros fatores que de acordo com Malta (2005, p. 17) é "[...] um conjunto de conceitos e de crenças que temos e que aceitamos como verdade em relação a nós mesmos, à nossa capacidade e ao que podemos fazer por nós." Portanto, a autoestima é uma consequência de pensamentos e atitudes geradas internamente e externamente.

Oliveira (1983) avalia a autoestima profissional dos bibliotecários, com base em valores ocupacionais e pessoais, a saber: inovação, independência, cultura, profundidade, criatividade, desenvoltura, espírito liberal e liderança. Em complemento ao pensamento exposto, Mendes et al. (2012, p. 7) afirma que:

[...] a autoimagem é uma descrição que a pessoa faz de si, a forma como ela se vê, estando esta percepção também relacionada ao modo como os outros a percebem. Por seu turno, a autoestima é uma avaliação que o sujeito faz de si, estando esta valoração relacionada também com o modo como os outros o avaliam.

A autoestima pode ser essencial para formar a imagem que 0 profissional transmite para os usuários, colegas e chefias num equipamento informacional, visto que ela impacta diretamente no relacionamento com a equipe, além de influenciar na produtividade e desempenho de sua função. Se a autoimagem deste profissional estiver abalada, possivelmente o seu desempenho não será o mesmo. Da mesma forma, se sua autoestima não for positiva, ela interferirá diretamente na autoimagem.

Diante do exposto, compreende-se que a autoimagem está ligada com a maneira que o indivíduo se vê, ou seja, os seus pensamentos relacionados aos seus próprios sentimentos, conhecimento de si mesmo e suas potencialidades positivas e negativas. A autoestima está ligada 
com os sentimentos e atitudes próprias do indivíduo. Ressalta-se que tanto a autoimagem quanto a autoestima podem ser influenciadas pela imagem que a sociedade faz de um profissional.

Como o foco deste artigo é discutir sobre a interferência desses fatores na mediação do bibliotecário, a seguir apresentam-se alguns discursos que fundamentam a ideia proposta.

\section{MEDIAÇÃO DA INFORMAÇÃO E A INTERFERÊNCIA DO BIBLIOTECÁRIO ESCOLAR}

A palavra mediador, deriva do latim mediatore, e significa aquele que medeia ou intervém. Em linhas gerais, o mediador é o facilitador de qualquer relação. Para Japiassú e Marcondes (1990, p. 164), mediação é "[...] em um sentido genérico, a ação de relacionar duas ou mais coisas, de servir de intermediário ou 'ponte', de permitir a passagem de uma coisa à outra." No entanto, defende-se que a mediação não exerce apenas o papel de uma ponte, que é estática; pois possibilita mais do que isso, lida com conflitos e diferentes circunstâncias.

O profissional da informação medeia a informação a alguém que possui uma necessidade informacional. Portanto, pratica esse ato pensando no usuário, foco do seu trabalho. Reconhecendo outra razão para a mediação, Santos e Gomes (2010) sugerem que:

[...] o bibliotecário, mediador da informação, é aquele que interage com dois desejos, o primeiro é o seu próprio desejo, que possibilita desenvolver atividades tradicionais como também inovadoras, que tenham por objetivo o acesso, uso e apropriação da informação pelo usuário. E o segundo desejo é singular dos sujeitos: o desejo de ter acesso à informação, apropriarse desse e atribuir sentido.

Infere-se a partir deste pensamento que, ao atender ao primeiro desejo, o bibliotecário planeja e executa suas atividades, podendo modificar a imagem que the é concedida. Ao lidar com o segundo desejo, que é próprio do usuário, demonstra interesse e cuidado com o 
João Arlindo dos Santos Neto, Tatiane de Fatima Farina Interferência da autoimagem do bibliotecário escolar na mediação da informação

fazer direcionado a satisfação da necessidade do sujeito. Acredita-se que ao lidar com esses desejos, o profissional da informação altere sua autoimagem e autoestima.

Ao discutir sobre as práticas de informação que ocorrem nas unidades de informação, é fundamental apresentar o conceito atualizado de Almeida Júnior (2015, p. 25), segundo o autor a mediação da informação é:

Toda ação de interferência - realizada em um processo, por um profissional da informação e na ambiência de equipamentos informacionais -, direta ou indireta; consciente ou inconsciente; singular ou plural; individual ou coletiva; visando a apropriação de informação que satisfaça, parcialmente e de maneira momentânea, uma necessidade informacional, gerando conflitos e novas necessidades informacionais.

Sendo assim, toda a ação realizada pelo bibliotecário se torna uma forma de mediar a informação para seus usuários. O fazer bibliotecário tem como base as necessidades e interesses da sua comunidade na construção de mecanismos para permitir aos usuários a apropriação da informação (ALMEIDA JÚNIOR, 2006). No conceito exposto enfatiza-se a interferência, que "[...] não deve ser negada, mas, sim, explicitada, afirmada, tornada consciente para que, criticamente, o profissional possa lidar com ela de maneira a amenizar/minimizar possíveis problemas que dela decorram." (ALMEIDA JÚNIOR, 2009, p. 94).

Assim, a interferência se dá em todos os momentos da mediação, pois a atuação do bibliotecário não é imparcial. Para Almeida Júnior e Bortolin (2008, p. 74), "O profissional da informação, mesmo buscando a imparcialidade - e sabendo que ela nunca será alcançada - deve se preocupar com a relação muito próxima entre interferência e manipulação.", pois ele é o mediador e deve, portanto, engendrar mecanismos para abolir a manipulação em todo o processo de mediação. 
Dessa maneira, pensar na mediação da informação sem a interferência é inadequado, porque tanto o mediador quanto usuário interferem no caminho e no resultado proveniente da busca da informação.

Atenta-se também que na mediação, o bibliotecário deve ser ético e possuir um perfil com habilidades específicas, a fim de que os serviços sejam adaptados a cada usuário, de acordo com suas particularidades. Segundo as diretrizes da IFLA/UNESCO a função do bibliotecário escolar:

[...] é contribuir para a missão e para os objectivos da escola, entre bibliotecas, em relação a outras modalidades incluindo os processos de avaliação, e para desenvolver e promover os da biblioteca escolar. [...] O seu conhecimento, as suas competências e a sua perícia vão ao encontro das necessidades de uma comunidade escolar específica. Para lá disso, ele deve conduzir campanhas de leitura e a promoção da literatura, dos media e da cultura para crianças. (IFLA/UNESCO, 2000, p. 11).

Para exercer essas funções, o bibliotecário deve possuir "[...] conhecimentos e habilidades necessárias para proporcionar o provimento e a solução de problemas de informação, além de ser um especialista no uso de todo o tipo de fontes, tanto na forma impressa como eletrônica." (MACEDO; OLIVEIRA, 2005, p. 13). Ele tem funções indispensáveis numa unidade de informação, principalmente em uma biblioteca escolar, onde se lida ao mesmo tempo com a mediação da informação, mas também com a mediação pedagógica, alfabetização científica, letramento informacional etc.

Enfatiza-se a biblioteca escolar como um dos primeiros ambientes onde os sujeitos possuem contato com um bibliotecário. Dessa forma, esse espaço contribui para a formação da imagem da figura desse profissional. Assim como as pessoas se lembram da sua primeira professora, espera-se que elas também se recordem do primeiro bibliotecário em sua vida. 
Segundo Fragoso (2002) a biblioteca escolar possui duas funções fundamentais: a educativa e a cultural. $\mathrm{Na}$ função educativa, ela representa um reforço à ação do aluno e do professor, desenvolvendo habilidades de estudo independente, agindo como instrumento de autoeducação, motivando a uma busca do conhecimento, incrementando a leitura e ainda auxiliando na formação de hábitos e atitudes de manuseio, consulta e utilização do livro, da biblioteca e da informação. Em sua função cultural, a biblioteca de uma escola torna-se complemento da educação formal, ao oferecer múltiplas possibilidades de leitura e, com isso, leva os alunos a ampliar seus conhecimentos e suas ideias acerca do mundo.

Ao investigar exemplos de bibliotecários que modificaram o espaço da biblioteca com projetos diferenciados para seus usuários e, consequentemente, transformaram a sua imagem profissional, pode-se citar como exemplo uma bibliotecária de uma escola particular de Marília, cidade do interior de São Paulo, que dinamizou o espaço com uma proposta pedagógica inovadora chamada Confraria da Biblioteca.

Conforme destacam Lanzi, Vidotti e Ferneda (2013) a Confraria da Biblioteca alia educação e tecnologia na formação do aprendiz, seja ele aluno regular de escolas públicas ou particulares, ou usuário de centros de inclusão em comunidades menos favorecidas. Com a criação de perfis em redes sociais e no blog Tumblr, essa realidade passou a fazer parte da rotina de estudos e de convivência de alunos e professores. Após a implantação da Confraria da Biblioteca, os autores relatam que houve melhorias no desempenho dos alunos e mudanças no seu posicionamento em relação ao aprendizado e a tecnologia.

O envolvimento do bibliotecário com outras atividades além daquelas corriqueiras de uma biblioteca possibilita que os usuários estabeleçam uma interação com o ambiente informacional de maneira dinâmica, permitindo a eles acessar materiais diversos. Nessa perspectiva, verificou-se a necessidade de investigar a imagem e autoimagem do bibliotecário no seu ambiente de trabalho, sobre como 
ele se auto avalia e considera a repercussão de suas ações no seu cotidiano, para que possa mediar a informação na biblioteca escolar.

\section{PROCEDIMENTOS METODOLÓGICOS}

O trabalho teve por objetivo investigar se a autoimagem dos bibliotecários escolares interfere na mediação da informação e analisar como essa interferência ocorre nos processos e nas práticas informacionais. Caracteriza-se como pesquisa descritiva, que segundo Cervo, Bervian e Silva (2007, p. 61) "[...] procura descobrir, com a maior precisão possível, a freqüência com que um fenômeno ocorre, sua relação e conexão com outros, sua natureza e suas características."

O método aplicado foi a pesquisa de campo que de acordo com Gil (2008, p. 53) "[...] procura muito mais o aprofundamento das questões propostas do que a distribuição das características da população segundo determinadas variáveis."

O instrumento utilizado para a coleta de dados foi o questionário, que "[...] refere-se a um meio de obter respostas às questões por uma fórmula que o próprio informante preenche." (CERVO; BERVIAN, 1996, p. 138). Este tipo de instrumento possibilita obtenção dos resultados de maneira mais concisa.

Dividiu-se o questionário em oito questões abertas e fechadas, com o intuito de investigar como a autoimagem e a autoestima do bibliotecário interferem nas ações de mediação da informação na biblioteca escolar. As questões do questionário tiveram o intuito de descobrir:

1) o motivo pelo qual os bibliotecários escolheram essa profissão;

2) se os bibliotecários se sentem valorizados no local onde trabalham;

3) por quem eles percebem que são mais reconhecidos;

4) qual a importância do trabalho que eles realizam na biblioteca escolar; 
5) o entendimento dos bibliotecários quanto a autoimagem profissional;

6) o nível em que se encontra a autoimagem deles;

7) os fatores que interferem em sua autoimagem; e,

8) se a autoimagem interfere na mediação da informação.

O universo da pesquisa engloba os bibliotecários da cidade de Londrina/PR, mas a população delimitada foram os bibliotecários de escolas públicas e particulares da Cidade, num total de 21. Após contatar os referidos profissionais, obteve-se o retorno de seis participantes da pesquisa.

Para análise dos dados, utilizou-se a técnica da categorização das respostas tendo como influência a Análise do Conteúdo. Segundo Bardin (2004, p. 33), essa forma de analisar dados representa "um conjunto de técnicas de análise das comunicações, que utiliza procedimentos sistemáticos e objetivos de descrição do conteúdo das mensagens.". A referida autora defende que a análise de conteúdo fundamenta-se em codificar, categorizar um segmento do texto para entender o seu sentido.

Sendo assim, a partir do conteúdo expresso no discurso dos respondentes, definiu-se categorias específicas e que são apresentadas com o uso de quadros e gráficos, a seguir.

\section{RESULTADOS E DISCUSSÃO}

Todos os bibliotecários que retornaram os questionários respondidos atuam em bibliotecas escolares de diferentes regiões de Londrina, sendo 2 de escolas públicas e 4 de escolas privadas. Do total, apenas um é do sexo masculino. Para manter o anonimato dos respondentes, eles foram identificados pelas letras A, B, C, D, E e F.

$\mathrm{Na}$ primeira questão, foi perguntado ao sujeito o que o levou a fazer o curso de Biblioteconomia, as respostas são apresentadas no quadro a seguir: 
João Arlindo dos Santos Neto, Tatiane de Fatima Farina Interferência da autoimagem do bibliotecário escolar na mediação da informação

Quadro 1: Análise das respostas da questão 1

\begin{tabular}{|c|c|}
\hline Sujeitos & Categorias \\
\hline A & Experiência \\
\hline B & Falta de opção \\
\hline C e F & Nível superior \\
\hline D & Amor pelos livros e pela biblioteca \\
\hline E & Vaga remanescente \\
\hline
\end{tabular}

Fonte: Dados da pesquisa.

Pode-se analisar que o curso de Biblioteconomia é buscado por vários motivos segundo as respostas dos sujeitos. $O$ participante $A$ afirmou que escolheu porque foi contratado para trabalhar como auxiliar de biblioteca e depois de dois anos resolveu fazer o curso, portanto, definiu-se a categoria experiência.

$\mathrm{O}$ respondente $\mathrm{B}$ afirmou que foi por falta de opção, o C e $\mathrm{F}$ optaram pelo curso para ter um diploma de nível superior, o $\mathrm{D}$ optou pela escolha devido ao amor que sente pelos livros e pelas bibliotecas e o $E$ disse que foi devido às vagas remanescentes ofertadas pela UEL.

$\mathrm{Na}$ segunda questão foi questionado se os bibliotecários se sentem valorizados na instituição em que trabalham e por quem. As repostas são apresentadas no gráfico 1 e no quadro 2:

Gráfico 1: Análise das respostas da questão 2

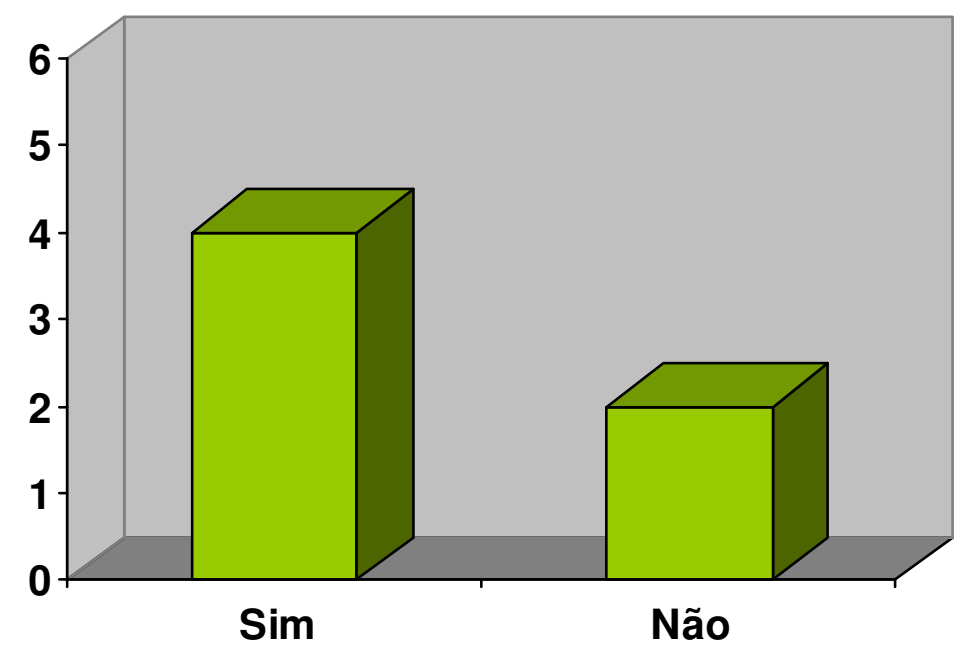

Fonte: Dados da pesquisa. 
A maioria dos respondentes afirmou se sentir valorizado na instituição em que trabalha, apenas dois sujeitos afirmaram que não se sentem valorizados. Em relação a quem os profissionais acreditam receber a valorização, a análise encontra-se no quadro 2 :

Quadro 2: Análise das respostas da questão 3

\begin{tabular}{|c|c|}
\hline Sujeitos & Categorias \\
\hline B, D, E F & Alunos \\
\hline E & Membros da equipe pedagógica \\
\hline C, E & Professores \\
\hline A & Poucas pessoas \\
\hline
\end{tabular}

Fonte: Dados da pesquisa.

Verifica-se que a valorização do trabalho do bibliotecário é percebida principalmente pelos alunos. Por serem bibliotecários escolares, acredita-se que as atividades executadas são com foco nos alunos e por esse motivo o reconhecimento seja mais lembrado por eles. Dois sujeitos ( $C$ e $E$ ) afirmaram receber a valorização pelos professores e somente um respondente $(E)$ pela equipe pedagógica. $A$ valorização do bibliotecário também pode ser percebida por poucas pessoas, segundo o sujeito $A$, talvez essa situação aconteça devido ao contexto escolar que esse bibliotecário está inserido.

O Manifesto da Biblioteca Escolar da IFLA/Unesco, ressalta com muita clareza o trabalho conjunto em prol da biblioteca escolar e do conhecimento de seus usuários. A parceria entre o bibliotecário e o pedagogo deveria ser harmoniosa, em cada escola e, em geral, não costuma ser (IFLA/UNESCO, 2000). Essa parceria é de suma importância para o ambiente escolar, sendo necessárias algumas mudanças nesse comportamento, com o intuito de, propiciar uma ação educativa e informacional conjunta para o fortalecimento do processo de aprendizagem, do fomento à leitura e da aquisição de competências, pelos alunos, para o uso da informação. 
João Arlindo dos Santos Neto, Tatiane de Fatima Farina

Interferência da autoimagem do bibliotecário escolar na mediação da informação

$\mathrm{Na}$ quarta questão foi solicitado que os bibliotecários classificassem a importância do seu trabalho num grau de 1 a 5, as respostas são apresentadas no gráfico 2:

Gráfico 2: Análise das respostas da questão 4

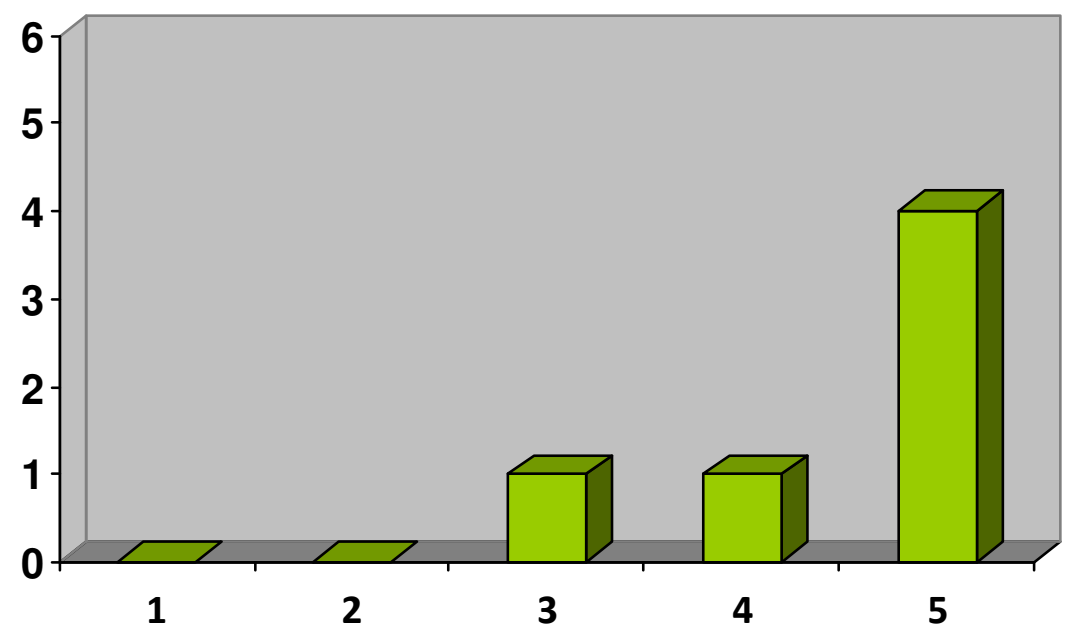

Fonte: Dados da pesquisa.

Em maior número, quatro bibliotecários classificaram que o seu trabalho é muito importante para eles, ou seja, consideram que o bibliotecário é fundamental para o ambiente em que atuam. Um profissional afirmou possuir importância média e outro ser importante. Verifica-se nesse posicionamento que nem todos os bibliotecários se consideram muito importante. Essa constatação faz com que se perceba que a autoestima de dois profissionais esteja abalada.

O bibliotecário escolar é o membro profissionalmente qualificado, responsável pelo planejamento e gestão da biblioteca escolar. Deve ser apoiado tanto quanto possível por equipe adequada, trabalha em conjunto com todos os membros da comunidade escolar e deve estar em sintonia com bibliotecas públicas e outros. (IFLA/UNESCO, 2010, p.3).

Fica evidente a importância que o bibliotecário exerce para o contexto escolar neste Manifesto. O bibliotecário escolar que trabalha em conjunto com toda a comunidade escolar deixa evidente sua 
importância na fase de aprendizagem do aluno no decorrer do ano escolar, bem como demonstra suas habilidades e conhecimentos a equipe pedagógica da escola.

Quando questionado o entendimento dos bibliotecários sobre a autoimagem profissional, os resultados foram:

Quadro 3: Análise das respostas da questão 5

\begin{tabular}{|c|c|}
\hline Sujeitos & Categorias \\
\hline A & Reconhecimento \\
\hline B e E & Valorizado \\
\hline C e F & Desafios \\
\hline D & Informado e atualizado \\
\hline
\end{tabular}

Fonte: Dados da pesquisa.

Verificou-se que os bibliotecários relacionam o conceito de autoimagem a diversos elementos. $O$ reconhecimento e a valorização são desafios para que essa imagem seja transmitida para os usuários, como aponta o sujeito $A$, ao afirmar que muitos profissionais têm se esforçado para que essa imagem seja positiva, pois ainda falta reconhecimento no País. Já os sujeitos $B$ e $E$ acreditam que 0 profissional tem buscado seu espaço e assim atendendo a demanda das necessidades informacionais de todas as pessoas que procuram um bibliotecário.

Os sujeitos $\mathrm{C}$ e $\mathrm{F}$ destacam que um profissional que é desafiado pelas novas tecnologias deve buscar uma constante atualização e adaptação com as responsabilidades impostas principalmente no início da carreira profissional. $O$ sujeito $D$ relata que se manter informado e preparado constantemente, contribuirá para a imagem que será transmitida para os seus leitores, de uma pessoa em que se pode confiar e com quem se pode contar. Alerta-se, no entanto, que o sujeito D confundiu autoimagem com imagem profissional.

Com o objetivo de descobrir como os bibliotecários percebem que está a sua autoimagem profissional, foi pedido também que eles 
João Arlindo dos Santos Neto, Tatiane de Fatima Farina

Interferência da autoimagem do bibliotecário escolar na mediação da informação

classificassem em qual nível (1-5) está sua autoimagem, conforme o gráfico abaixo.

Gráfico 3: Análise das respostas da questão 6

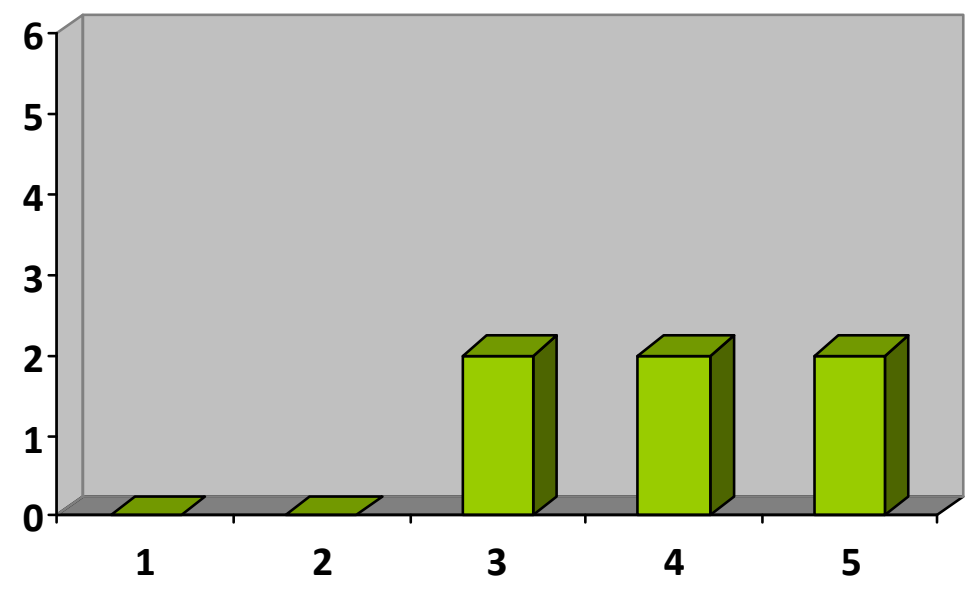

Fonte: Dados da pesquisa.

De todos os respondentes pode-se analisar que a percepção da autoimagem é positiva, mas abaixo da média de acordo com o gráfico. Os bibliotecários acreditam que de 1 a 5, sua autoimagem está no nível 2, o que representa uma baixa autoimagem. Segundo Oliveira (1983, p. 71), "[...] muito da realidade do campo precisa ser mudado, para que a Biblioteconomia possa, sem perda de sua identidade de trabalho eminentemente social, acompanhar a mudança que está ocorrendo na ambiência em que atua." Em relação aos fatores que interferem na autoimagem, os bibliotecários evidenciaram os seguintes:

Quadro 4: Análise das respostas da questão 7

\begin{tabular}{|c|c|}
\hline Sujeitos & Categorias \\
\hline A & Reconhecimento \\
\hline B & Fatores intrínsecos \\
\hline C & Piso salarial \\
\hline D e E & Informação \\
\hline F & Profissionais \\
\hline
\end{tabular}

Fonte: Dados da pesquisa. 
Constatou-se que diferentes fatores interferem na autoimagem profissional para os bibliotecários escolares. Como é destacado novamente pelo sujeito $A$, a falta de reconhecimento do trabalho que um bibliotecário exerce, faz com que ele seja vetado em trabalhos que gostaria de desenvolver na biblioteca em que atua, fazendo com que sua autoimagem fique oprimida, ou seja, podendo se tornar uma autoimagem negativa. Grogan (1995, p. 12) afirma que "[...] a transformação da imagem estereotipada do bibliotecário não será resultado da fabricação de uma 'contra-imagem', nem da alteração do 'rótulo' profissional, mas sim mudar a realidade por trás da imagem e deixar que esta cuide de si mesma."

$O$ sujeito $B$ também acredita que apenas fatores intrínsecos interferem, considera o seu comportamento e as atitudes como fator de interferência para desenvolver suas atividades. $O$ sujeito $C$ ressalta a falta de um piso salarial para a categoria, apesar de pagar a anuidade ao Conselho Regional de Biblioteconomia do Paraná (CRB Região 9) ainda não há uma faixa salarial regulamentada para escolas particulares, há uma convenção para os órgãos estaduais.

Para que a informação seja disseminada para o usuário é necessário que o profissional mediador dela também esteja bem informado, é o que alegam os sujeitos $D$ e $E$, que afirmam buscar atender bem a todos que frequentam a sua biblioteca, fazendo com que seus leitores saiam com suas dúvidas resolvidas, encontrando as informações que necessitam. Já o sujeito $F$ caracteriza também o vestuário do bibliotecário, o modo de falar e como eles se comportam ao desenvolver as tarefas de bibliotecário, isto é, a sua postura profissional.

Ao questionar se a autoimagem pode interferir na mediação da informação, os possíveis motivos apontados pelos respondentes são apresentados no quadro 5 : 
Quadro 5: Análise das respostas da questão 8

\begin{tabular}{|c|c|}
\hline Sujeitos & Categorias \\
\hline A & Função sem restrição \\
\hline B & Melhorias \\
\hline C & Usuários \\
\hline D & Consciência \\
\hline E & Autoimagem negativa \\
\hline F & Ser seguro \\
\hline
\end{tabular}

Fonte: Dados da pesquisa.

As opiniões se divergem quanto a interferência da autoimagem profissional na mediação da informação. Ressalta-se que mediar é, também, o modo como as ações bibliotecárias complementam a visão do usuário sobre determinados assuntos e como analisam os usuários. Para o sujeito $A$ quando é permitido exercer a função do bibliotecário sem restrição, ou seja, desenvolver projetos de leitura, teatros, eventos com contação de histórias, a mediação da informação está em pleno desenvolvimento. $O$ sujeito $B$ destaca que se o profissional se possui uma autoimagem positiva, ele se valoriza e consequentemente vai valorizar e buscar melhorar a condição dos outros. O sujeito $C$ complementa que se os usuários não entenderem como o bibliotecário poderá ajudá-lo, eles não irão procurá-lo.

A imagem que o bibliotecário transmite para o leitor, e a consciência disto não são suficientes, mas atender o usuário com eficiência como argumenta o sujeito $D$. Para o sujeito $E$, só prejudica se o profissional tem uma autoimagem negativa, ou seja, o modo como ele se reconhece e se relaciona com os outros.

Infere-se que as respostas dessa última pergunta atenderam na superficialidade o esperado pela questão. Uma hipótese é a de que talvez os bibliotecários não saibam o que a mediação da informação representa, portanto, não conseguiram vislumbrar como a autoimagem pode interferir nos processos mediativos. Tendo findado a análise e discussão dos dados, apresenta-se as considerações finais do artigo. 


\section{CONSIDERAÇÕES FINAIS}

Considera-se a importância da autoimagem na mediação da informação, pois é a imagem que o bibliotecário irá transmitir para seu usuário no momento do atendimento, podendo ser positiva ou negativa, que vai refletir na sua visibilidade social. Pode-se perceber que a autoimagem por ser um tema delicado e intrínseco, causa alguns estranhamentos nos sujeitos, muitos hesitam em tratar esse assunto.

Alguns fatores como a valorização profissional, influenciam a autoimagem que tem ligação direta com a autoestima do indivíduo, ou a noção do seu próprio valor no local de trabalho. Partindo desse pressuposto, o foco principal deste artigo foi analisar se a autoimagem dos bibliotecários escolares interfere na mediação da informação.

Vale ressaltar que a baixa autoestima não está somente ligada à própria imagem, mas também à sociedade, pois, o profissional está, na maioria das vezes, se relacionando com os usuários da instituição em que está inserido, o que permite ser comparado ou mesmo menosprezado quanto à sua formação ou no cargo que atua. A mediação se torna presente no dia a dia do bibliotecário e para que ele possa mediar à informação, é necessário também se preparar para receber esse usuário.

Diante disso, conclui-se que a mediação da informação interfere nas práticas informacionais do bibliotecário, sendo afetadas pela sua autoimagem, que apresentando positivamente ou negativamente, 0 usuário poderá se apropriar da informação ou não. Consequentemente, o usuário irá construir uma imagem distorcida do bibliotecário ou ainda não se apropriar da informação, uma vez que a autoimagem interfere na mediação.

Faz-se necessário continuar com questionamentos a respeito da autoimagem, pois a profissão bibliotecária está passando por diversas mudanças sociais. Influências tecnológicas estão impactando na imagem e na atuação do bibliotecário, permitindo assim conferir como o 
indivíduo se relaciona com essas transformações e que, possivelmente, interferem na sua atuação profissional, em sua mediação.

\section{REFERÊNCIAS}

ALMEIDA JÚNIOR, Oswaldo Francisco de. Mediação da informação: ampliando o conceito de disseminação. In: VALENTIM, Marta Lígia Pomim. Gestão da informação e do conhecimento no âmbito da Ciência da Informação. São Paulo: Polis; Cultura Acadêmica, 2008, p. 41-54.

Mediação da Informação: ampliando o conceito de disseminação. In: ENCONTRO DE EDUCADORES E INVESTIGADORES EN BIBLIOTECOLOGIA, ARCHIVOLOGIA, CIENCIAS DE LA INFORMACIÓN Y DE LA DOCUMENTACIÓN DE IBEROAMÉRICA Y EL CARIBE (EDIBCIC), 7., 2006. Marília. Anais... Marília: UNESP, 2006. (CD-ROM).

. Mediação da informação e múltiplas linguagens. Pesq. bras. Ci. Inf., Brasília, v. 2, n. 1, p. 89 -103, jan./ dez. 2009. Disponível em: <http://inseer.ibict.br/ancib/index.php/tpbci/article/view/17/39>. Acesso em: 15 nov. 2015.

Mediação da informação: um conceito atualizado. In:

BORTOLIN, Sueli; SANTOS NETO, João Arlindo; SILVA, Rovilson José da (Org.). Mediação oral da informação e da leitura. Londrina: Abecin, 2015, p. 9-32.

ALMEIDA JÚNIOR, Oswaldo. Francisco de; BORTOLIN, Sueli. Mediação da informação e da leitura. In: SILVA, Terezinha Elisabeth da (Org). Interdisciplinaridade e Transversalidade em Ciência da Informação. Recife: Néctar, 2008, p. 67-85.

BARDIN, Laurence. Análise de conteúdo. 3.ed. Lisboa: Edições 70, 2004.

CERVO, Amado Luiz; BERVIAN, Pedro Alcino. Metodologia científica. São Paulo: Makron Books, 1996.

CERVO, Amado Luiz; BERVIAN, Pedro Alcino; SILVA, Roberto da. Metodologia científica. São Paulo: Pearson, 2007. 
FARINA, Tatiane de Fatima. Autoimagem do bibliotecário escolar e a mediação da informação. 2014. 61 f. Trabalho de Conclusão de Curso (Graduação em Biblioteconomia) - Universidade Estadual de Londrina, Londrina, 2014.

FERREIRA, Aurélio Buarque de Holanda. Novo dicionário Aurélio da língua portuguesa. 4 ed. Curitiba: Positivo, 2009.

FRAGOSO, Graça Maria. Biblioteca na escola. Rev. ACB, Biblioteconomia em Santa Catarina, v. 7, n. 1, 2002. p. 124-131. Disponível em: <http://revista.acbsc.org.br/racb/article/view/380/460>. Acesso em: 28 nov. 2015.

GIL, Antonio Carlos. Como elaborar projetos de pesquisa. 4. ed. São Paulo: Atlas,2008.

GOUVEIA, Valdiney Veloso et al. Auto-imagem e sentimento de constrangimento. PSICO, Porto Alegre, PUCRS, v. 36, n. 3, p. 231-241, set./dez. 2005. Disponível em:

<http://revistaseletronicas.pucrs.br/ojs/index.php/revistapsico/article/view /1393/1093>. Acesso em: 18 nov. 2015.

GROGAN, Denis Joseph. A prática do serviço de referência. Brasília, DF: Briquet de Lemos, 1995.

IFLA/ UNESCO. Manifesto IFLA/UNESCO para biblioteca escolar. Tradução Neusa Dias Macedo. São Paulo: IFLA, 2000. Disponível em: <http://archive.ifla.org/VII/s11/pubs/portuguese-brazil.pdf> Acesso em: 25 nov. 2015.

JAPIASSÚ, Hilton; MARCONDES, Danilo. Dicionário básico de filosofia. Rio de Janeiro: Jorge Zahar, 1990.

LANZI, Lucirene Andréa Catini; VODOTTI, Silvana Aparecida Borsetti Gregorio; FERNEDA, Edberto. A biblioteca escolar e a geração nativos digitais: construindo novas relações. São Paulo: Cultura acadêmica, 2013. Disponível em:

<http://repositorio.unesp.br/handle/11449/109286>. Acesso em: 10 out. 2015.

LIMA, Cátia Cristina de; LIMA, Katianne de. A auto-imagem do bibliotecário Versus a visão social: uma análise da valorização Profissional. 2009, 83 f. Trabalho de conclusão de curso (Graduação em Biblioteconomia) - Universidade Federal de Alagoas, Maceió, 2009.

Disponível em:

<http://www.ichca.ufal.br/graduacao/biblioteconomia/v1/wpcontent/uploads/tcc-2009-catia-e-katianne-a-auto-imagem-dobibliotecario.pdf >. Acesso em: 15 dez. 2015. 
MACEDO, Neusa Dias; OLIVEIRA, Helena Gomes. Diretrizes da IFLA / UNESCO para a biblioteca escolar, São Paulo, 2005. Disponível em: <http://www.ifla.org/files/assets/school-libraries-resourcecenters/publications/school-library-guidelines/school-library-guidelinespt_br.pdf>. Acesso em: 23 nov. 2015.

MALTA, Schielley. Eu, caçador de mim: a busca da auto-estima. Indaiatuba: SilvaNews, 2005.

MENDES, Aline Rocha et al. Autoimagem, autoestima e autoconceito: contribuiç̃ões pessoais e profissionais na docência. In: SEMINÁRIO DE PESQUISA EM EDUCAÇÃO DA REGIÃO SUL, 9., 2012, Caxias do Sul, Anais eletrônicos... Caxias do Sul: UCS, 2012. p. 1-13. Disponível em: $<$ http://www.ucs.br/etc/conferencias/index.php/anpedsul/9anpedsul/pape r/viewFile/724/374>. Acesso em: 15 nov. 2015.

MOSQUERA, Juan José Mouriño; STOBÄUS, Claus Dieter. Autoimagem, auto-estima e auto-realização na universidade. In: ENRICONE, Délcia (Org.). A docência na educação superior: sete olhares. 2. ed. Porto Alegre: EDIPUCRS, 2008. p. 111-128.

OLVEIRA, Andriê Bezerra de. Considerações acerca do estereótipo dos bibliotecários: apontando mudanças de atitude do profissional frente à sociedade contemporânea. 2010. 83f. Trabalho de Conclusão de Curso (Graduação em Biblioteconomia) - Universidade Federal do Rio Grande do Norte, Natal, 2010. Disponível em:

<http://monografias.ufrn.br/jspui/bitstream/1/88/1/Andri\%C3\%AABO_Mo nografia.pdf>. Acesso em: 15 nov. 2015.

OLIVEIRA, Zita Catarina Prates de. O bibliotecário e sua autoimagem. São Paulo: Pioneira, 1983.

SANTOS, Raquel do Rosário; GOMES, Henriette Ferreira. A mediação da informação nos websites das bibliotecas de universidades públicas brasileiras: o uso dos dispositivos de comunicação. In: ENCONTRO NACIONAL DE PESQUISA EM CIÊNCIA DA INFORMAÇÃO

(ENANCIB), 11., 2010. Anais eletrônicos...Rio de Janeiro: IBICT, 2010. Disponível em: <http://congresso.ibict.br/index.php/xi/enancibXl/paper/view/145/110>. Acesso em:

02 dez. 2015.

WALTER, Maria Teresa Machado Teles; BAPTISTA, Sofia Galvão. A força dos estereótipos na construção da imagem profissional dos bibliotecários, Inf. \& Soc.: Est., João Pessoa, v. 17, n. 3, p.27-38, set./dez. 2007. Disponível em: <http://www.ies.ufpb.br/ojs/index.php/ies/article/view/962/1583>. Acesso em: 15 nov. 2015. 
João Arlindo dos Santos Neto, Tatiane de Fatima Farina

Interferência da autoimagem do bibliotecário escolar na mediação da

informação

\section{Title}

Interference of self image librarian school in mediation of information

\section{Abstract}

Introduction: Analyzes the self image of the school librarian of private and public schools in Londrina. Discusses the self-image terms, image and selfesteem in the context of professional information.

Objectives: Investigate the self-image of school librarians interfere in the information mediation and checks such interference occurs in processes and informational practices.

Methodology: It presents a qualitative research of descriptive character, from a literature review and also exploratory. Uses field research as a method and the questionnaire with open and closed for data collection issues.

Results: Notes that school librarians are influenced in their actions by the selfimage, as well as other factors influence the mediation, such as image and selfesteem of the professional.

Conclusions: We conclude that the self-image of the school librarian interferes with the mediation of information. The image of the librarian, in turn, is also constructed from their acts of mediation and self-esteem librarian contributes to building your professional image.

Keywords: Self image. Librarian self-image. School librarian. Mediation of information. School library.

\section{Titulo}

La interferencia de la autoimagem del bibliotecario escolar en la mediación de la información

Resumen

Introducción: Analiza la propia imagen del bibliotecario escolar de las escuelas públicas y privadas en Londrina. Discute los términos de autoestima, la imagen y la autoestima en el contexto de la información profesional.

Objetivos: Investigar la imagen de sí mismo de los bibliotecarios escolares interfieren en la mediación de la información y los controles tal interferencia se produce en los procesos y las prácticas informativas.

Metodología: Se presenta una investigación cualitativa de carácter descriptivo, a partir de una revisión de la literatura y también exploratoria. Utiliza la investigación de campo como método y el cuestionario con preguntas abiertas y cerradas por cuestiones de recopilación de datos.

Resultados: Toma nota de que los bibliotecarios escolares están influenciados en sus acciones por parte de la imagen de sí mismo, así como otros factores que influyen en la mediación, como la imagen y la autoestima del profesional.

Conclusiones: Concluimos que la auto-imagen del bibliotecario de la escuela interfiere con la mediación de la información. La imagen del bibliotecario, a su vez, también se construye a partir de sus actos de mediación y bibliotecario autoestima contribuye a la construcción de su imagen profesional. 
Palabras clave: Concepto de sí mismo. Bibliotecario imagen de sí mismo. Bibliotecario de la escuela. Información de la mediación. Biblioteca de la escuela.

Recebido em: 26.12.2015

Aceito em: 20.03.2016 